\title{
Impact of Hybrid Renewable Energy Systems on Short Circuit Levels in Distribution Networks
}

\author{
S. N. Afifi \\ Brunel University, UK \\ Sara.Afifi@brunel.ac.uk
}

\author{
M. K. Darwish \\ Brunel University, UK \\ Mohamed.darwish@brunel.ac.uk
}

\begin{abstract}
The effects of the distributed generation can be classified as environmental, technical and economical effects. It is playing a very vital role for improving the voltage profiles in electrical power systems. However, it could have some negative impacts such as operating conflicts for fault clearing and interference with relaying. Distribution system is the link between the utility system and the consumer. It is divided into three categories radial, Loop, and network. Distribution networks are the most commonly used to cover huge number of loads. The power system reliability mainly depends on the smooth operation and continuity of supply of the distribution network. However, this may not always be guaranteed especially with the introduction of distributed generation to the distribution network. This paper will examine the impact of hybrid renewable energy systems (using photovoltaic and doubly fed induction generators) on short circuit level of IEEE 13-bus distribution test system using ETAP software.
\end{abstract}

Index Terms-Distributed generation, photovoltaic, renewable energy, short circuit current, wind energy.

\section{INTRODUCTION}

The Distributed generation (DG) is deemed to be an ultimate solution to various environmental, technical, political, and economical obstacles. Nowadays, it is playing a vital role for improving the voltage profiles in electrical power systems networks. The rapid increasing of DG penetration into distribution networks requests intensive technical analysis to determine its impact. This is to validate its robust relevance for installation to ensure smooth reliable operation of the distribution networks [1]-[6].

The short-circuit phenomenon is one of the most important factors causing transients in electrical power systems. Voltage sources in electrical power systems have a tendency to donate in a fault during short circuit. However, the distributed generation may have some negative effects such as operating conflicts for fault clearing and interference with relaying. Accordingly, efforts considering DG penetration levels are presently underway to make a compromise between their positive and the negative impacts [2].

DG is commonly defined as small size generators (up to 300 megawatts) that provide active electric power, connected directly to the distribution network or to the network on the customer site of the meter. Renewable energy sources (such as wind, wave, and solar energy), combined heat and power, and standby generators are considered as common types of DG [6], [7]. Fig. 1 shows the DG classification according to the principles of operation and the interface between the grid and the DG-unit. This classification is important to determine the short-circuit contribution of the DG to a disturbance in the distribution network [8].

The wind and photovoltaic (PV) represented 2.3\% and $15 \%$ respectively, of the global power generation capacity in 2012. The deployment of wind and PV power generation has experienced an accelerating rapid expansion in recent years, particularly in Europe. The variability and uncertainty in wind speed and level of solar irradiance, and resource location are direct implications for the integration of wind and PV into the distribution networks [9].

The short circuit capacity is a fundamental characteristic in considering a reliable and secure distribution power system. A principal requirement for connecting a DG to distribution networks is that, the short-circuit level (SCL) at the point of common coupling, where the renewable energy source will be connected to, should not exceed the network designed value [10], [11]. However, the short circuit capacity of existing distribution networks is often close to its design value, leaving a limited margin for the possibility of DG connection. The uncertainty of short-circuit current contribution by DG is a major constraint in connecting the DG to distribution networks [12], [13]. Selection of DG location, rating, and type has substantial effect of the short circuit level.

In this paper, the impact of location and size of a hybrid renewable energy system including PV and Type-3 wind turbine generator (WTG) on short-circuit level of IEEE 13bus distribution test system using ETAP software will be examined. This will include different types of faults such as three-phase (3-phase), single-line to ground (LG), line to line (LL) and double-line to ground (LLG). In addition, a detailed comparison between three case studies: PV system, Type-3 WTG system, and a hybrid renewable energy system will be presented and discussed. The study considered the same distribution system, the same scenarios regarding the same location and the size of DG used. This paper is organized as follows, on which the present context forms Section I as an introduction to the work. Section II is devoted to the configuration of the hybrid system. Section III gives the case study. The simulated results and the comparison between the different scenarios are discussed in Section IV. The conclusion is presented in Section V. 


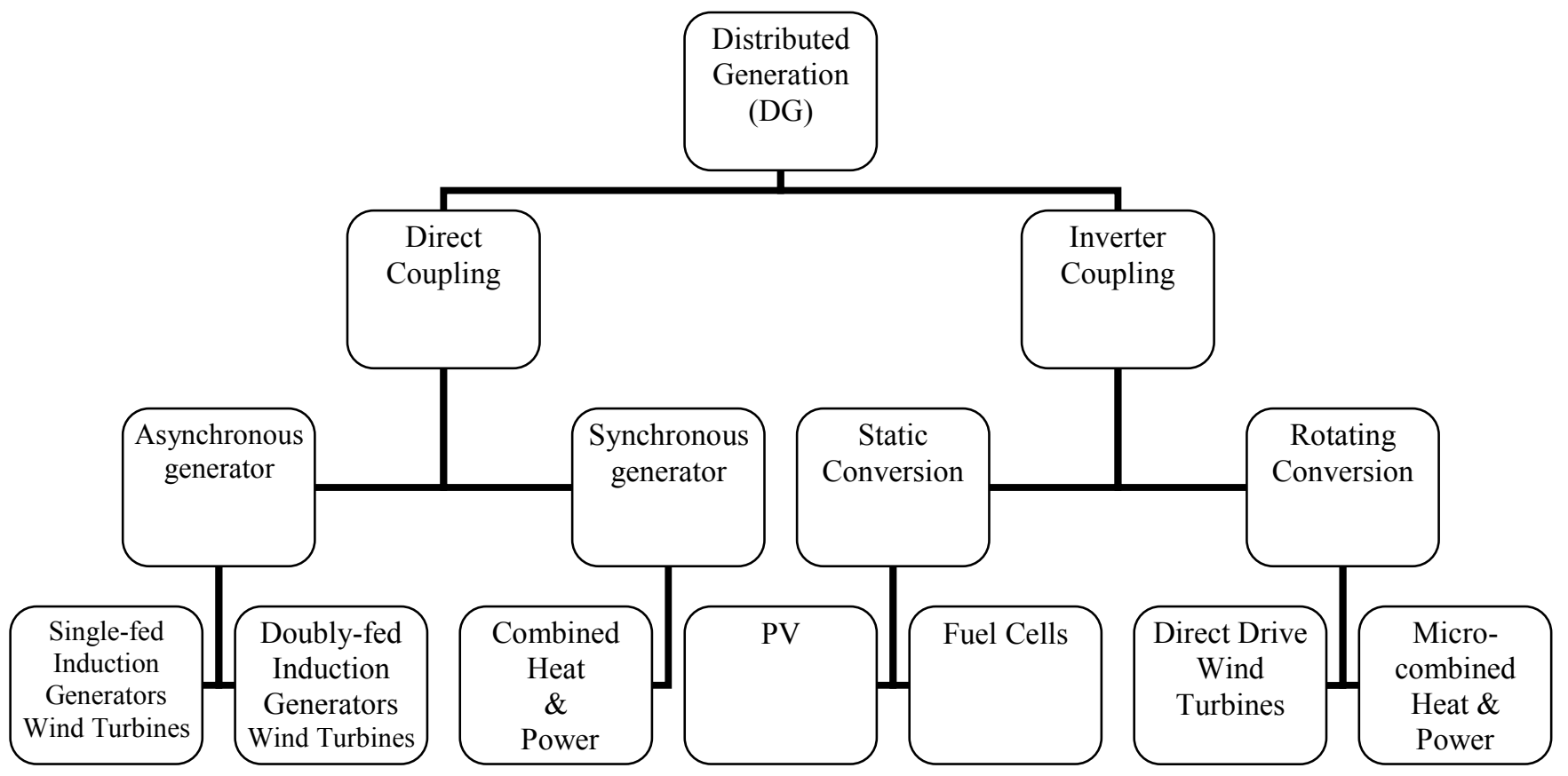

Fig. 1. General classification of DG according to the principle of operation and the interface between the grid and the DG-unit [8].

\section{CONFIGURATION OF THE HYBRID SYSTEM}

\section{A. Doubly Fed Induction Generators}

Wind turbines classification is based on the generator, speed control (fixed or variable) and interface with the grid (via power electronics equipment). The variable speed generators offer more advantages over fixed speed generators including $20-30 \%$ higher energy generation, lower mechanical stress, and less fluctuating electric output power [14]. There are four types of wind turbines: Fixed speed conventional induction generator (Type-1); variable slip, induction generators with variable rotor resistance (Type-2); variable speed doubly fed induction generators with rotorside converter also known as doubly fed asynchronous generators (Type-3); and variable speed asynchronous generators with full converter interface (Type-4) [15]. In this paper, the variable speed doubly fed induction generators (DFIG) (Type-3) is the DG used.

The DFIG is the most widely used in the wind power industry. DFIG is principally a wound rotor induction machine, where the rotor circuit is connected through external power electronics converters, and the stator is connected directly to the grid. This feature offers remotely adjustable and controllable power quality and variable speed operation. The rotor windings are connected to the grid through back back converters as shown in Fig. 2. for the DFIG schematic diagram. A major advantage of DFIG is that, active and reactive power fed to the grid from the stator are controlled independently from the generator turning speed, thus, providing a constant source of active power and voltage with variable wind turbine speed. The generator rotor speed is adjusted to operate within $\pm 30 \%$ of synchronous speed. Hence, the generator system can operate in both subsynchronous and super-synchronous mode. The power rating of the converter circuit is typically around $25-30 \%$ of the nominal rated power output of the wind turbine. It is capable of generating the maximum output power during limited wind speed availability. The low power losses in the converters enhance the overall efficiency [15], [17], [18].

\section{B. Photovoltaic Power System}

The photovoltaic represented the fastest growing renewable power technology worldwide over the last decade [19]. 'Photovoltaic effect' is the process where direct sunlight is converted into electrical energy. This process takes place in the main building block of a PV power system, photovoltaic cell. "The PV cells are grouped in series and parallel circuits to form a PV module. Hence, numbers of PV modules are electrically connected in a series-parallel configuration to generate the required current and voltage [4]. The PV array output power is affected by the operating conditions and the site conditions such as geometric location, irradiance level, and ambient temperature [14], [20]. Photovoltaic system is divided into stand-alone photovoltaic system and gridconnected photovoltaic system. Their application depends upon the load function and operation conditions. Gridconnected photovoltaic system operates in parallel with and interconnected with the utility grid. Fig. 3. shows a fundamental PV power generation system [21]. 


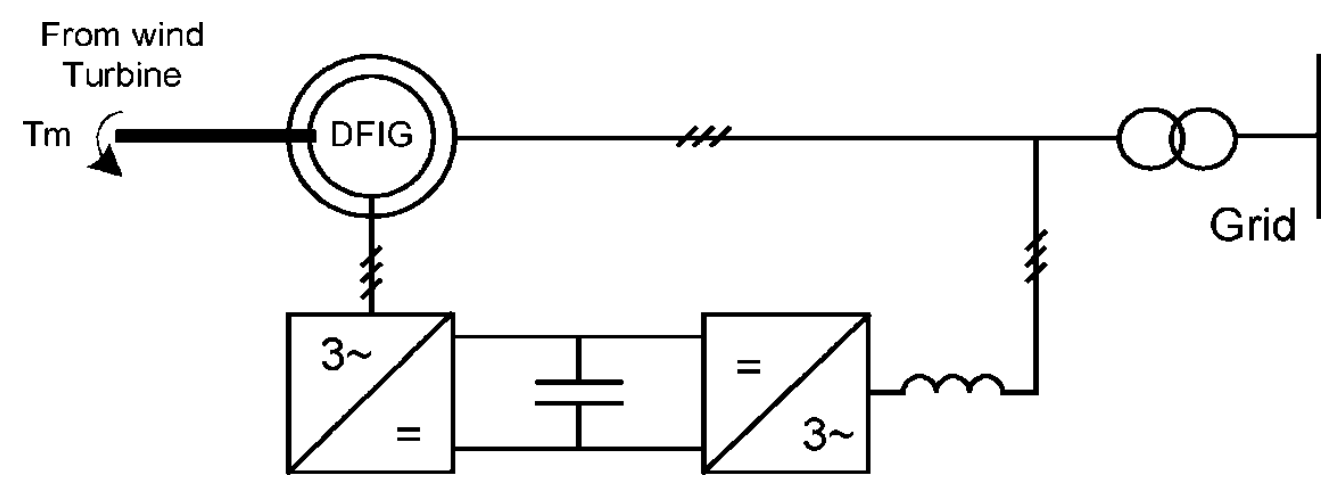

Fig. 2. DFIG (Type-3) Wind Energy System Schematic Diagram [16].

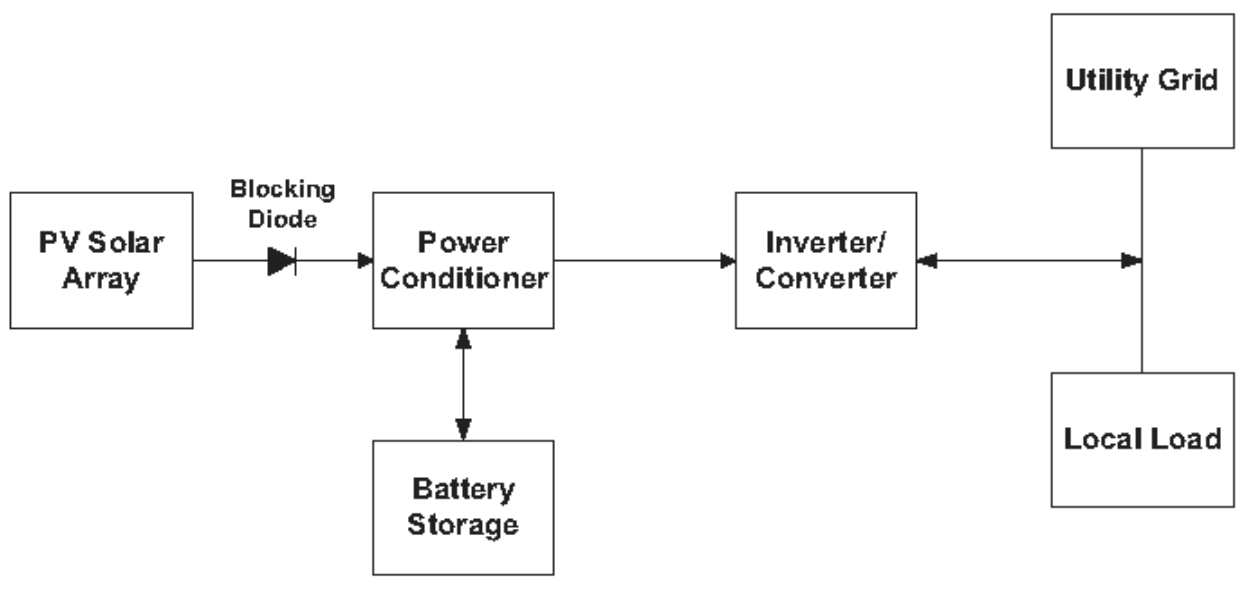

Fig. 3. Block Diagram of photovoltaic power system [20].

The PV modules are connected to the grid through inverters, to convert the DC output power from the PV modules into AC. The impact of connecting large scale PV farms to distribution networks on the system power quality and reliability remains uncertain. Energy storage; varying solar irradiance profile; locations of solar availability; system voltage profile; and harmonics are significant challenges preventing the vast deployment of grid connected PV systems [3], [5], [22], [23].

\section{SYSTEM UNDER STUDY}

The short-circuit analysis has been examined on the IEEE 13-bus distribution test system using ETAP software as a simulation tool. The single-line diagram of the examined system is shown in Fig. 4. The IEEE 13-bus distribution test system data is given in Table I. Four scenarios are examined in regards to the DG location from the main grid, the most loaded bus, and the DG size variation, as follows

- Scenario 1 (S1) has no DG installed.

- Scenario 2 (S2) has 1.5 MW Type-3 WTG and 1.5 MW PV farm placed at bus 632 .

- Scenario 3 (S3) has 1.5 MW Type-3 WTG and 1.5 MW PV farm placed at bus 675.

- Scenario 4 (S4) has 1.5 MW Type-3 WTG placed at bus 632 and 1.5 MW PV farm at bus 671.

The specifications and rated capacity of the PV array used are as follows:

Short-circuit current, $\mathrm{I}_{\mathrm{SC}}=7.47$ amperes,

Open circuit voltage, $\mathrm{V}_{\mathrm{OC}}=21.97$ volts,

The maximum power, $\mathrm{P}_{\mathrm{MAX}}=120.3$ watts,

The current for maximum power, $\mathrm{I}_{\mathrm{MP}}=6.91$ amperes,

The voltage for maximum power, $\mathrm{V}_{\mathrm{MP}}=17.41$ volts, and Solar Irradiance is $1000 \mathrm{~W} / \mathrm{m}^{2}$.

TABLE I

LOAD DATA

\begin{tabular}{c|c|c|c|c|c|c|c}
\hline \hline Node & Load & Ph-1 & Ph-1 & Ph-2 & Ph-2 & Ph-3 & Ph-3 \\
\hline & Model & $\mathrm{kW}$ & $\mathrm{kVAr}$ & $\mathrm{kW}$ & $\mathrm{kVAr}$ & $\mathrm{kW}$ & $\mathrm{kVAr}$ \\
\hline 634 & Y-PQ & 160 & 110 & 120 & 90 & 120 & 90 \\
\hline 645 & Y-PQ & 0 & 0 & 170 & 125 & 0 & 0 \\
\hline 646 & D-Z & 0 & 0 & 230 & 132 & 0 & 0 \\
\hline 652 & Y-Z & 128 & 86 & 0 & 0 & 0 & 0 \\
\hline 671 & D-PQ & 385 & 220 & 385 & 220 & 385 & 220 \\
\hline 675 & Y-PQ & 485 & 190 & 68 & 60 & 290 & 212 \\
\hline 692 & D-I & 0 & 0 & 0 & 0 & 170 & 151 \\
\hline 611 & Y-I & 0 & 0 & 0 & 0 & 170 & 80 \\
\hline & TOTAL & 1158 & 606 & 973 & 627 & 1135 & 753 \\
\hline \hline
\end{tabular}




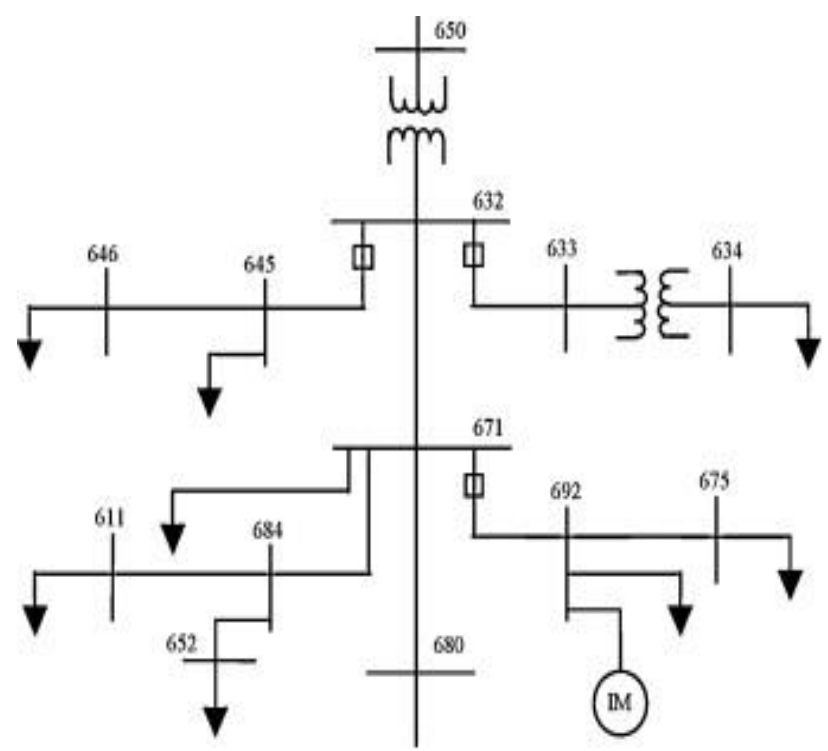

Fig. 4. Single-Line diagram of the IEEE 13-Bus Distribution TeSt SYSTEM.

\section{RESULTS AND DISCUSSION}

The short circuit analysis testing the impact of hybrid system on IEEE 13- bus distribution system for the four types of fault for the four different scenarios is presented in Table II.

TABLE II

HYBRID SYSTEM SIMULATED RESULTS FOR SHORT-CIRCUIT FAULT CURRENTS IN KILO-AMPERES (KA)

\begin{tabular}{c|c|c|c|c}
\hline \multirow{2}{*}{ Location of Fault } & \multicolumn{4}{|c}{ 3-Phase Fault } \\
\cline { 2 - 5 } & S1 & S2 & S3 & S4 \\
\hline Bus 632 & 11.276 & 12.392 & 12.028 & 12.366 \\
\hline Bus 671 & 6.453 & 6.72 & 7.516 & 6.79 \\
\hline Bus 675 & 5.771 & 5.979 & 6.886 & 6.018 \\
\hline & \multicolumn{4}{|c}{ Line to Ground Fault } \\
\cline { 2 - 5 } & S1 & S2 & S3 & S4 \\
\hline Bus 632 & 8.463 & 8.948 & 8.787 & 8.941 \\
\hline Bus 671 & 4.536 & 4.64 & 4.922 & 4.661 \\
\hline Bus 675 & 4.181 & 4.267 & 4.606 & 4.280 \\
\hline & \multicolumn{5}{|c}{ Line-to-Line Fault } \\
\hline & S1 & S2 & S3 & S4 \\
\hline Bus 632 & 9.766 & 10.95 & 10.545 & 10.928 \\
\hline Bus 671 & 5.588 & 5.868 & 6.712 & 5.929 \\
\hline Bus 675 & 4.998 & 5.216 & 6.178 & 5.250 \\
\hline & \multicolumn{4}{|c}{ Line-to-Line Ground Fault } \\
\cline { 2 - 5 } & S1 & S2 & S3 & S4 \\
\hline Bus 632 & 10.631 & 11.76 & 11.360 & 11.752 \\
\hline Bus 671 & 5.903 & 6.17 & 6.956 & 6.183 \\
\hline Bus 675 & 5.277 & 5.479 & 6.409 & 5.515 \\
\hline \hline
\end{tabular}

The study considered the same distribution system, the same scenarios in regards to the same location and the size of DG used. These case studies were PV, Type-3 WTG, and hybrid renewable energy system (PV and Type-3 WTG).
TABLE III

DFIG SYSTEM SIMULATED RESULTS FOR SHORT-CIRCUIT FAULT CURRENTS IN KILO-AMPERES (KA) [15]

\begin{tabular}{c|c|c|c|c}
\hline \hline \multirow{2}{*}{ Location of Fault } & \multicolumn{4}{|c}{ 3-Phase Fault } \\
\cline { 2 - 5 } & $\mathrm{S} 1$ & $\mathrm{~S} 2$ & $\mathrm{~S} 3$ & $\mathrm{~S} 4$ \\
\hline Bus 632 & 11.276 & 13.318 & 12.577 & 13.030 \\
\hline Bus 671 & 6.453 & 6.922 & 8.423 & 7.731 \\
\hline Bus 675 & 5.771 & 6.143 & 7.813 & 6.768 \\
\hline & \multicolumn{4}{|c}{ Line to Ground Fault } \\
\cline { 2 - 5 } & $\mathrm{S} 1$ & $\mathrm{~S} 2$ & $\mathrm{~S} 3$ & $\mathrm{~S} 4$ \\
\hline Bus 632 & 8.463 & 9.337 & 9.010 & 9.217 \\
\hline Bus 671 & 4.536 & 4.717 & 5.203 & 5.001 \\
\hline Bus 675 & 4.181 & 4.333 & 4.910 & 4.569 \\
\hline Bus 632 & \multicolumn{5}{|c}{ Line-to-Line Fault } \\
\hline Bus 671 & S1 & S2 & S3 & S4 \\
\hline Bus 675 & 9.766 & 11.967 & 11.103 & 11.639 \\
\hline & 5.588 & 6.083 & 7.681 & 6.962 \\
\hline Bus 632 & 4.998 & 5.389 & 7.190 & 6.062 \\
\hline Bus 671 & Line-to-Line Ground Fault \\
\hline Bus 675 & 10.631 & S2 & S3 & S4 \\
\hline \hline & 5.903 & 6.398 & 7.954 & 7.268 \\
\hline & 5.277 & 5.657 & 7.482 & 6.303 \\
\hline
\end{tabular}

TABLE IV

PV SYSTEM SIMULATED RESULTS FOR SHORT-CIRCUIT FAULT CURRENTS IN KILO-AMPERES (KA) [21]

\begin{tabular}{c|c|c|c|c}
\hline \hline \multirow{2}{*}{ Location of Fault } & \multicolumn{4}{|c}{ 3-Phase Fault } \\
\cline { 2 - 5 } & $\mathrm{S} 1$ & $\mathrm{~S} 2$ & $\mathrm{~S} 3$ & $\mathrm{~S} 4$ \\
\hline Bus 632 & 11.276 & 11.494 & 11.435 & 11.464 \\
\hline Bus 671 & 6.453 & 6.51 & 6.644 & 6.579 \\
\hline Bus 675 & 5.771 & 5.807 & 6.014 & 5.847 \\
\hline & \multicolumn{4}{|c}{ Line to Ground Fault } \\
\cline { 2 - 5 } & $\mathrm{S} 1$ & $\mathrm{~S} 2$ & $\mathrm{~S} 3$ & $\mathrm{~S} 4$ \\
\hline Bus 632 & 8.463 & 8.534 & 8.514 & 8.524 \\
\hline Bus 671 & 4.536 & 4.554 & 4.599 & 4.576 \\
\hline Bus 675 & 4.181 & 4.193 & 4.268 & 4.208 \\
\hline & \multicolumn{5}{|c}{ Line-to-Line Fault } \\
\cline { 2 - 5 } & $\mathrm{S} 1$ & $\mathrm{~S} 2$ & $\mathrm{~S} 3$ & $\mathrm{~S} 4$ \\
\hline Bus 632 & 9.766 & 9.954 & 9.903 & 9.928 \\
\hline Bus 671 & 5.588 & 5.638 & 5.754 & 5.697 \\
\hline Bus 675 & 4.998 & 5.029 & 5.209 & 5.063 \\
\hline & \multicolumn{5}{|c}{ Line-to-Line Ground Fault } \\
\cline { 2 - 5 } & S1 & S2 & S3 & S4 \\
\hline Bus 632 & 10.631 & 10.685 & 10.670 & 10.675 \\
\hline Bus 671 & 5.903 & 5.921 & 6.089 & 5.991 \\
\hline Bus 675 & 5.277 & 5.298 & 5.571 & 5.370 \\
\hline \hline
\end{tabular}

In comparing the three simulation results of wind; PV; and hybrid systems separately as given in Tables II, III,IV there has been always a noticeable common pattern. The highest SCL always happened in case of Scenario 2 for fault occurring at bus 632 for all types of fault. Subsequently, the SCL in case of scenario 3 at faults occurring at buses 671 and 675 respectively appeared to be always common in the three different systems under study. It must be noticed that the three-phase fault remained the most significant type of fault.

Finally, in evaluating the short-circuit current values for the three different systems; it is noticeable that it comes in ascending order as follows: wind system, hybrid system, and PV system. 


\section{CONCLUSIONS}

In this paper, the impact of location and size of a hybrid renewable energy system (PV and Type-3 WTG) on SCL of IEEE 13-bus distribution test system using ETAP software is presented.

This included four types of faults including three-phase, single-line to ground, line to line and double-line to ground. Moreover, a detailed comparison between three case studies implementing two different DG technologies has been presented. The study considered the same distribution system, the same scenarios regarding the same location and the size of DG used. These case studies were PV, Type-3 WTG, and hybrid renewable energy system (PV and Type3 WTG).

The Type-3 WTG system had the most significant impact on the SCL of the distribution test system. Conversely, the PV system had the least contribution on the SCL for the same distribution system.

Remarkably, the hybrid renewable energy system was moderate. It could be concluded that the optimal DG selection to maintain the distribution network designed short circuit capacity, is to deploy a DG mix. Typically, the DG allocation should be considered.

\section{REFERENCES}

[1] R. K. Sinha, R. Kumar. M.Venmathi, L. Ramesh, "Analysis of Voltage Sag with Different DG for Various Faulty Conditions," International Journal of Computer Communication and Information System, Vol. 2, No.1, July - Dec 2010.

[2] A. S. El Safty, B. M. Abd El Geliel, and C. M. Ammar, "Distributed Generation Stability during Fault Conditions,' International Conference on Renewable Energies and Power Quality, Granada, Spain, March 23-25, 2010.

[3] A.F. Zobaa and S.H.E. Abdel Aleem, "A New Approach for Harmonic Distortion Minimization in Power Systems Supplying Nonlinear Loads," IEEE Transactions on Industrial Informatics, Vol. 10, No. 2, pp. 1401-1412, May 2014.

[4] M. B. M. Rozlan, A. F. Zobaa and S. H. E. Abdel Aleem, "The Optimisation of Stand-Alone Hybrid Renewable Energy Systems Using HOMER," Int. Rev. of Elect. Eng., IREE 6(4B), pp. 1802-1810, Aug. 2011.

[5] S. H. E. Abdel Aleem, A. F. Zobaa, and A. C. M. Sung, "On the economical design of multiple-arm passive harmonic filters," in 47th International Universities' Power Engineering. Conf., UPEC'12, Uxbridge, Middlesex, United Kingdom, Sep. 4-7, 2012, pp. 1-6.

[6] L. L. Freris and D. G. Infield, Renewable Energy in Power Systems. Chichester: John Wiley \& Sons, 2008.

[7] T. Ackermann, G. Andersson and L. Soder, "Distributed generation: a definition" Electric Power Systems Research, Vol. 57, No. 3, pp. 195-204, April 2001.

[8] E. J. Coster. Distribution Grid Operation Including Distributed Generation. PhD. Thesis, Technical University of Eindhoven, Netherlands, Sep. 2010.

[9] WEO World Energy Outlook. (2013). Chapter 6- Renewable Energy Outlook [Online].

Available:http://www.worldenergyoutlook.org/media/weowebs ite/2013/WEO2013_Ch06_Renewables.pdf

[10] T. N. Boutsika and S. A. Papathanassiou, "Short-circuit calculations in networks with distributed generation," Electric Power Systems Research, Vol. 78, No. 7, pp. 1181-1191, July 2008.
[11] Baghaee, H. R.; Mirsalim, M.; Sanjari, M. J.; Gharehpetian, G.B., "Effect of type and interconnection of DG units in the fault current level of distribution networks," 13th Power Electronics and Motion Control Conference, Poznan, Sep. 1-3, 2008, pp. 313-319.

[12] Boljevic, S.; Conlon, M.F., "The contribution to distribution network short-circuit current level from the connection of distributed generation," 43rd International Universities Power Engineering Conference, Padova, Sep. 1-4, 2008, pp. 1-6.

[13] Barghi, Siamak; Golkar, Masoud Aliakbar; Hajizadeh, A., "Impacts of distribution network characteristics on penetration level of wind distributed generation and voltage stability," 10th International Conference on Environment and Electrical Engineering, Rome, May 8-11, 2011, pp. 1-4.

[14] M.R. Patel, Wind and Solar Power Systems Design, Analysis, and Operation, 2e. Taylor \& Francis, Florida, USA, 2006.

[15] S.N. Afifi; H. Wang; G.A. Taylor; M.R. Irving, "Impact of DFIG wind turbines on short circuit levels in distribution networks using ETAP," 48th International Universities' Power Engineering Conference, Dublin, Sep. 2-5, 2013, pp. 1-4.

[16] Lie Xu and P. Cartwright, "Direct active and reactive power control of DFIG for wind energy generation," IEEE Transactions on Energy Conversion, Vol. 21, No. 3, pp. 750758, September 2006.

[17] E. Gursoy and R. A. Walling, "Representation of variable speed wind turbine generators for short circuit analysis," Electrical Power and Energy Conference, Winnipeg, MP, Oct. 3-5, 2011, pp. 444-449.

[18] B. Wu, Y. Lang, N. Zargari and S. Kouro, Power Conversion and Control of Wind Energy Systems. Wiley-IEEE Press, 2011.

[19] IEA International Energy Agency. (2013). topic: Solar (PV and CSP) [Online].

Available: http://www.iea.org/topics/solarpvandesp/

[20] G.K. Singh, "Solar power generation by PV (photovoltaic) technology: A review," Energy, Vol. 53, pp. 1-13, May 2013.

[21] S.N. Afifi, M.K. Darwish, G.A. Taylor, "Impact of photovoltaic penetration on short circuit levels in distribution networks," International Conference on Renewable Energy and Power Quality Conference, Cordoba, Spain, April 8-10, 2014.

[22] Yun Tiam Tan; Kirschen, D.S., "Impact on the Power System of a Large Penetration of Photovoltaic Generation," Power Engineering Society General Meeting, Tampa, FL, June 24-28, 2007, pp. 1-8.

[23] Tae-Hun Kim, Ju-Han Lee, et al., "Operation characteristic analysis of Three-phase grid connected PV system with AF and STATCOM," Vehicle Power and Propulsion Conference, Seoul, Korea, October 9-12, 2012, pp. 9-12. 